\title{
COMMUNICATION
}

Cite this: DOI: $10.1039 / \times 0 \times x 00000 x$

\section{A second-generation ligand for the enantioselective rhodium-catalyzed addition of arylboronic acids to alkenylazaarenes}

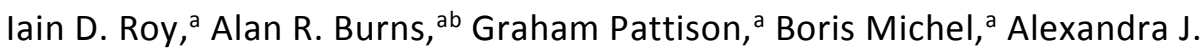 \\ Parker $^{\mathrm{c}}$ and Hon Wai Lam ${ }^{*}$ b
}

Received 00th January 2012, Accepted 00th January 2012

DOI: $10.1039 / \times 0 \times x 00000 x$

www.rsc.org/chemcomm

A 2,4,6-trialkylanilide-containing chiral diene has been identified as a superior ligand for the enantioselective rhodiumcatalyzed arylation of alkenylazaarenes with arylboronic acids.

As part of a program aimed at the preparation of enantioenriched chiral azaarene-containing compounds, ${ }^{1}$ we have focused upon an underexploited strategy in asymmetric synthesis, namely the utilization of the $\mathrm{C}=\mathrm{N}$ moiety within certain azaarenes to activate adjacent functionality in enantioselective catalysis. ${ }^{2-4}$ In this context, we have reported ${ }^{1 b}$ the enantioselective rhodium-catalyzed 1,4arylation $^{5-8}$ of $\beta$-substituted alkenylazaarenes with arylboronic acids using a secondary amide-containing chiral diene ${ }^{9-11}$ ligand L1 (see Table 1, entry 1), which builds upon early studies by the groups of Lautens $^{12 \mathrm{a}}$ and Genet ${ }^{12 \mathrm{~b}}$ using vinylazaarenes. Although L1 was highly effective, it was of interest to determine whether a ligand of this complexity, possessing stereochemical elements additional to those of the chiral diene component, was actually necessary for optimal results. ${ }^{13}$ Herein, we report a simpler ligand that provides results superior to those obtained using L1, along with a more comprehensive evaluation of the scope of the reaction.

First, various analogues of $\mathbf{L 1}$ were prepared and evaluated in the enantioselective addition of 4-methylphenylboronic acid to 2alkenylquinoline 1a (Table 1), a reaction that gave $\mathbf{2 a}$ in $67 \%$ yield Table 1 Ligand evaluation for arylation of $1 \mathbf{a}^{a}$

a EaStCHEM, School of Chemistry, University of Edinburgh, Joseph Black Building, The King's Buildings, West Mains Road, Edinburgh, EH9 3JJ, United Kingdom.

b School of Chemistry, University of Nottingham, University Park, Nottingham, NG7 2RD, United Kingdom.

Email: hon.lam@nottingham.ac.uk; Tel: +44-115-748-4677.

${ }^{c}$ AstraZeneca Process Research and Development, Charter Way, Silk Road Business Park, Macclesfield, Cheshire, SK10 2NA, United Kingdom.

$\dagger$ Electronic Supplementary Information (ESI) available: Experimental procedures, spectroscopic data for new compounds, and crystallographic data. CCDC 976345-976346. For ESI and crystallographic data in CIF See DOI: $10.1039 / \mathrm{b} 000000 \mathrm{x} /$

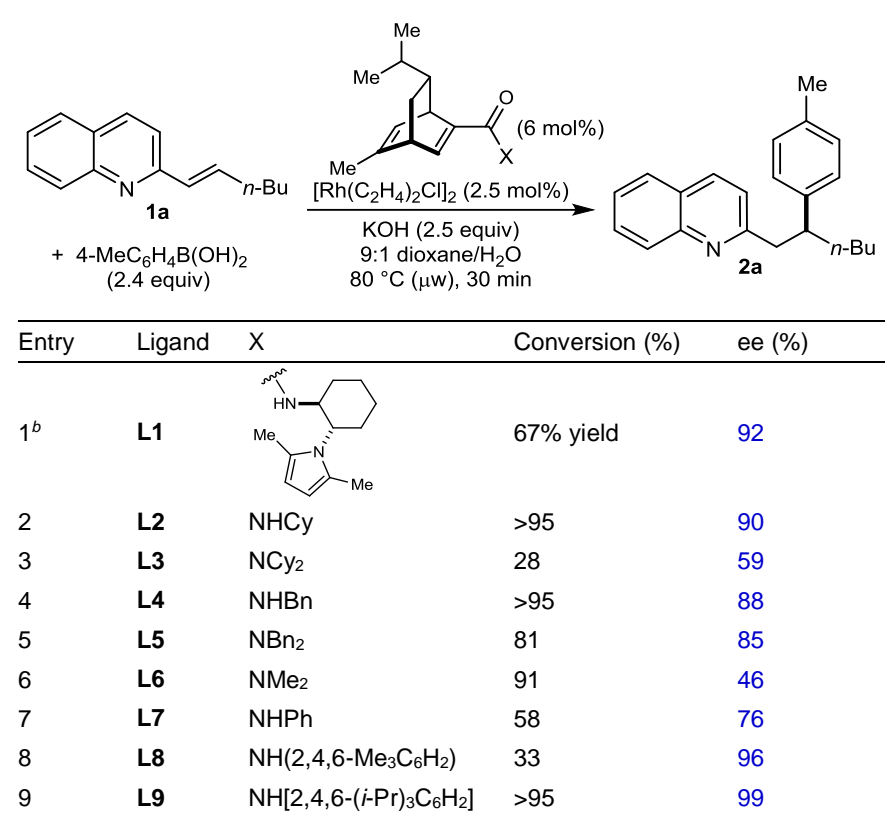

${ }^{a}$ Reactions were conducted using $0.10 \mathrm{mmol}$ of $\mathbf{1 a}(0.2 \mathrm{M})$. Conversions were determined by ${ }^{1} \mathrm{H}$ NMR analysis of the unpurified reaction mixtures. Enantiomeric excesses were determined by chiral HPLC analysis. ${ }^{b}$ Ref. $\mathrm{ib}$.

and $92 \%$ ee in our original study. ${ }^{1 \mathrm{~b}}$ The conditions employed were identical to those we described previously. ${ }^{1 b}$ Ligand $\mathbf{L 2}$, which lacks the pyrrole moiety on the cyclohexane, provided 2a in high conversion but the enantioselectivity was slightly lower (entry 2) compared with that obtained using L1 (entry 1). However, the dicyclohexylamide $\mathbf{L 3}$ was noticeably inferior (entry 3). Ligands L4 and L5, which contain one or two benzyl groups, respectively, provided reasonable results (entries 4 and 5), but the enantioselectivities were lower compared with L1. The dimethylamide $\mathbf{L 6}$ gave high conversion but the reaction was poorly Table $\mathbf{2}$ Comparison of ligand $\mathbf{L} \mathbf{9}$ with $\mathbf{L 1}^{a}$ 


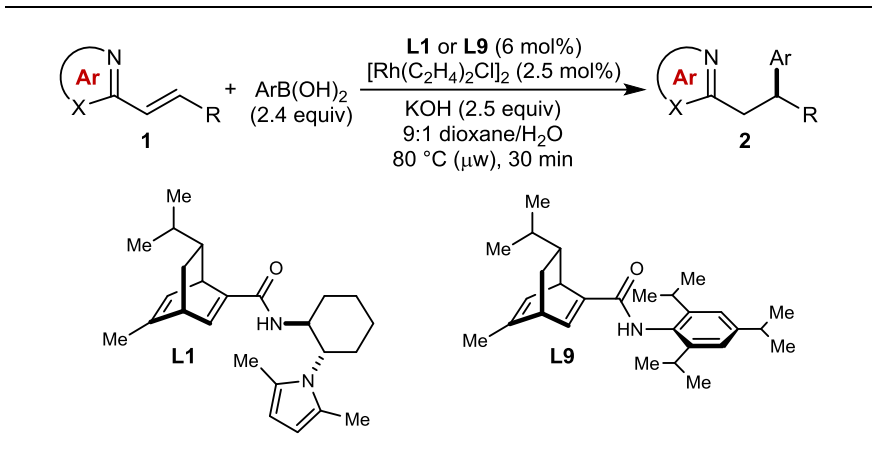

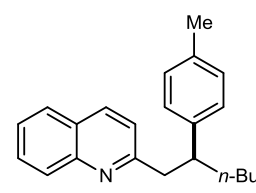

$2 a$

With L1: $67 \%, 92 \% \mathrm{ee}^{b}$ With L9: $76 \%$, 98\% ee<smiles>Cc1ccc(C(C)Cc2nc(-c3ccccc3)c(-c3ccccc3)o2)cc1</smiles>

With L1: $69 \%, 89 \% \mathrm{ee}^{b}$ With L9: $71 \%, 77 \%$ ee

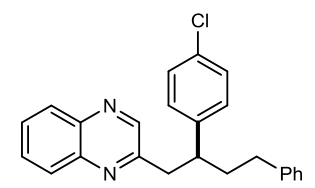

2b

With L1: $75 \%, 90 \% \mathrm{ee}^{b}$ With L9: $73 \%, 97 \%$ ee

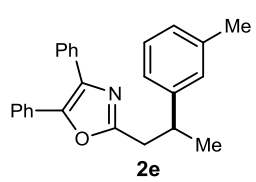

With L1: $95 \%, 87 \%$ ee With L9: $76 \%, 92 \% \mathrm{ee}^{c}$

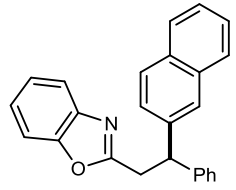

2c

With L1: 78\%, 93\% ee

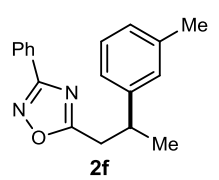

With L1: $64 \%, 94 \% \mathrm{ee}^{b}$ With L9: $69 \%, 97 \% \mathrm{ee}^{\mathrm{c}}$ With L9: $81 \%$, 99\% ee

${ }^{a}$ Reactions were conducted using $0.50 \mathrm{mmol}$ of alkenylazaarene $(0.2 \mathrm{M})$. Yields are of isolated material. Enantiomeric excesses were determined by chiral HPLC analysis. ${ }^{b}$ Results taken from ref. ${ }^{\mathrm{l} c}$ Reaction conducted using $0.30 \mathrm{mmol}$ of alkenylazaarene.

enantioselective (46\% ee, entry 6). Next, ligands L7-L9 containing anilide groups were studied (entries 7-9), and of these, the 2,4,6triisopropylanilide L9 provided the best results, giving $\mathbf{2 a}$ in $>95 \%$ conversion and $99 \%$ ee (entry 9).

Further confirmation of the superior enantioselectivities imparted by this new triisopropylanilide ligand L9 was provided by repeating representative reactions described in our original study ${ }^{1 \mathrm{~b}}$ using $\mathbf{L 9}$ in place of $\mathbf{L 1}$ (Table 2). These results indicate that while in most cases the isolated yields of the products with both ligands are comparable, the enantioselectivities are higher using $\mathbf{L 9}(\mathbf{2 a}, \mathbf{2 b}$, 2c, 2e, and 2f). One exception was the addition of 4methylphenylboronic acid to a substrate containing a 4,5diphenyloxazole as the activating group, which gave $\mathbf{2 d}$ in $77 \%$ ee using $\mathbf{L 9}$, and this result is inferior to that obtained using ligand $\mathbf{L 1}$ (89\% ee). Interestingly, the inferiority of $\mathbf{L 9}$ compared with $\mathbf{L 1}$ with this substrate appeared to be restricted to the use of 4methylphenylboronic acid; when 3-methylphenylboronic acid was employed, $\mathbf{L 9}$ provided the product $\mathbf{2 e}$ in a higher enantioselectivity. The reasons for these contrasting results are not currently known.

To explore the scope of the process with the second generation ligand $\mathbf{L 9}$ more comprehensively, a range of previously reported and new alkenylazaarenes were reacted with 4-methylphenylboronic acid (Table 3). While substrates containing pyrimidine or benzoxazole, azaarenes that have already been demonstrated to be efficient activating groups in our original study, ${ }^{1 \mathrm{~b}}$ underwent arylation Table 3 Arylation of alkenylazaarenes with 4-methylphenylboronic acid

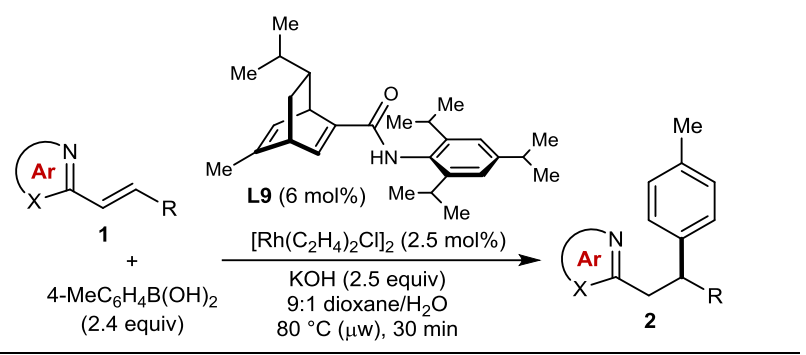

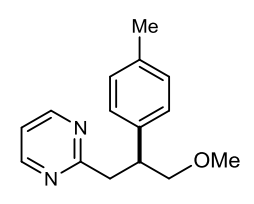

2g $77 \%, 99 \%$ ee<smiles>CCCCC(Cc1nc(-c2cccc(OC)c2)nc(-c2cccc(OC)c2)n1)c1ccc(C)cc1</smiles>

2h $48 \%, 99 \%$ ee

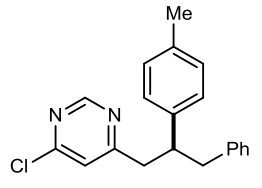

2i $78 \%, 99 \%$ ee<smiles>Cc1ccc(C(Cc2[X]c3ccccc3n2)c2ccccc2)cc1</smiles>

2k $X=0,72 \%, 99 \%$ ee $e^{b}$ 2l $\mathrm{X}=\mathrm{S}, 70 \%, 99 \%$ ee<smiles>Cc1ccc(C(Cc2nnc(-c3ccccc3)o2)c2ccc(Cl)cc2)cc1</smiles><smiles>Cc1ccc(C(Cc2nnn(C)n2)c2ccccc2)cc1</smiles>

2n $<5 \%$ conversion

${ }^{a}$ Reactions were conducted using $0.30 \mathrm{mmol}$ of alkenylazaarene $(0.2 \mathrm{M})$. Yields are of isolated material. Enantiomeric excesses were determined by chiral HPLC analysis. ${ }^{b}$ Enantiomeric excess determined after hydrolysis to the secondary amide. ${ }^{c}$ The stereochemistry of $\mathbf{2 m}$ was determined by X-ray crystallography, CCDC $976346 .{ }^{d}$ The structure of the alkenylazaarene substrate 1m was determined by X-ray crystallography, CCDC 976345.

efficiently with excellent enantioselectivities as expected (2g and $\mathbf{2 k}$ ), further examples demonstrate that other azaarenes are also effective. These examples include $\pi$-deficient azaarenes such as pyrazine (2h), a chloropyrimidine (2i), and a 4,6-bis(aryl)-1,3,5triazine (2j), as well as $\pi$-excessive azaarenes such as benzothiazole (2l), a 1,3,4-oxadiazole (2m), and a tetrazole (2o). A pyrazinecontaining substrate was only moderately reactive, providing product $\mathbf{2 h}$ in $48 \%$ yield, though in $99 \%$ ee. Although alkenyltetrazole $\mathbf{1 l}$ was unreactive (none of $\mathbf{2 n}$ was obtained), its regioisomer $\mathbf{1 m}$ provided 20 in $64 \%$ yield and $95 \%$ ee. The difference in reactivities between $1 \mathbf{l}$ and $\mathbf{1 m}$ can be understood by consideration of their conjugation patterns. Whereas the alkene is conjugated only with the $\mathrm{C}=\mathrm{N}$ group of the tetrazole in $\mathbf{1 1}$, it is conjugated with both the $\mathrm{C}=\mathrm{N}$ and $\mathrm{N}=\mathrm{N}$
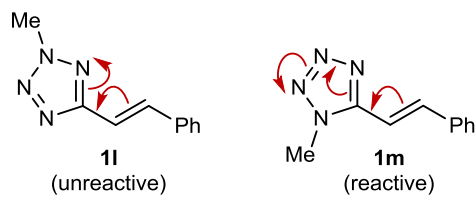

Fig. 1 Difference in conjugation between alkenyltetrazoles $\mathbf{1 l}$ and $\mathbf{1 m}$. Table 4 Arylation of alkenylazaarenes with various arylboronic acids 

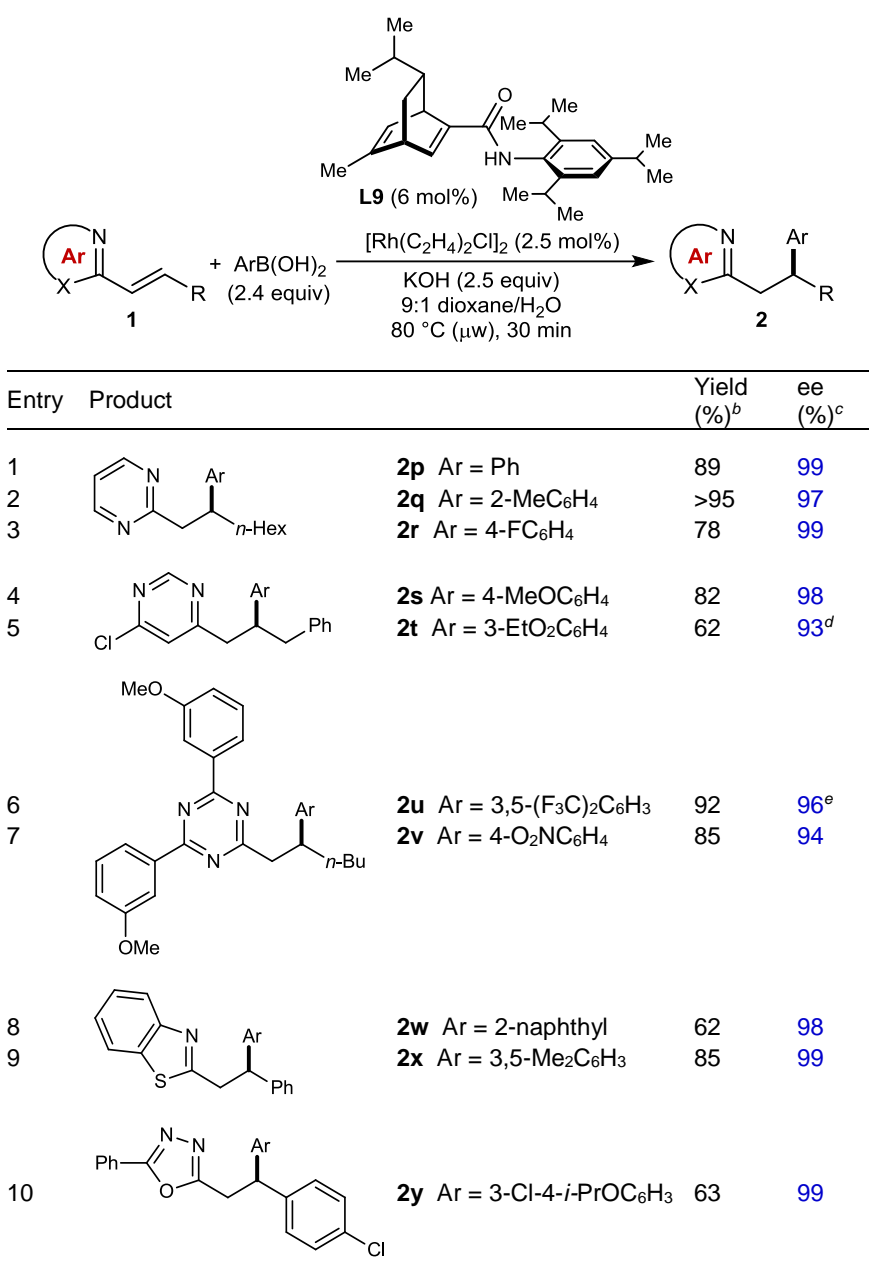

${ }^{a}$ Reactions were conducted using $0.30 \mathrm{mmol}$ of alkenylazaarene $(0.2 \mathrm{M}){ }^{b}$ Isolated yield. ${ }^{c}$ Determined by chiral HPLC analysis. ${ }^{d}$ Enantiomeric excess determined on a derivative obtained after treatment of $\mathbf{2 t}$ with $\mathrm{LiOH}$ in $\mathrm{THF} / \mathrm{MeOH} / \mathrm{H}_{2} \mathrm{O}$. ${ }^{e}$ Enantiomeric excess determined after demethylation of the methoxy groups using $\mathrm{BBr}_{3}$.

moieties in 1m, leading to a greater degree of activation (Fig. 1). With respect to the $\beta$-substituent on the alkene, the process is tolerant of simple alkyl groups ( $\mathbf{2} \mathbf{i}$ and $\mathbf{2} \mathbf{j}$ ), a cyclopropane (2h), an ether $(\mathbf{2 g})$, and aryl groups $(\mathbf{2 k}, \mathbf{2}, \mathbf{2} \mathbf{m}$, and $\mathbf{2 0})$.

A range of arylboronic acids are compatible with this process, as demonstrated by the results presented in Table 4. Arylboronic acids containing substituents such as methyl (entries 2 and 9), halogen (entries 3 and 10), or alkoxy (entries 4 and 10) groups reacted smoothly with various alkenylazaarenes in good yields and high enantioselectivities. Arylboronic acids containing strong electronwithdrawing groups such as ester, trifluoromethyl, or even nitro substituents were also effective (entries 5-7). A sterically encumbering ortho-substituent on the arylboronic acid was also tolerated (entry 2).

This process can also be conducted on a larger scale using lower loadings of the arylboronic acid and catalyst. For example, arylation of alkenylpyrimidine $\mathbf{1 h}$ on a $5.0 \mathrm{mmol}$ scale with 4methoxyphenylboronic acid ( 1.5 equiv), using thermal heating at 70

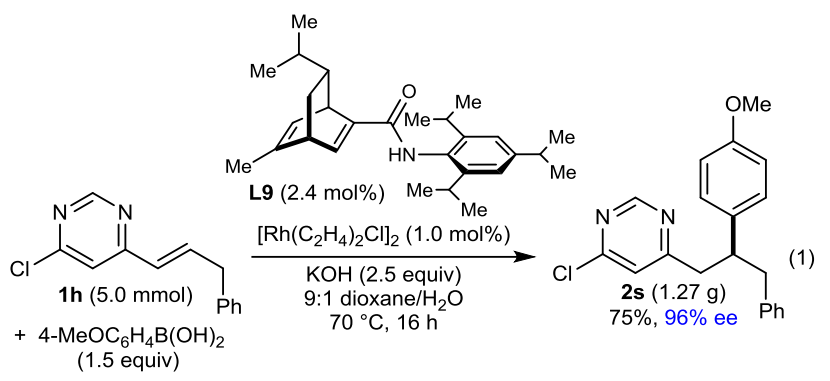

${ }^{\circ} \mathrm{C}$ in the presence of $2.0 \mathrm{~mol} \%$ of the rhodium-chiral diene complex, provided $2 \mathrm{~s}$ in $75 \%$ yield $(1.27 \mathrm{~g}$ ) and $96 \%$ ee (eq 1$)$.

In summary, a more in-depth evaluation of chiral diene ligands for the enantioselective addition of arylboronic acids to alkenylazaarenes has resulted in the identification of a secondgeneration ligand L9 containing a 2,4,6-triisopropylanilide moiety that is superior to our first generation ligand L1. Not only does this new chiral diene result in generally superior enantioselectivities, it is simpler in structure. A more thorough assessment of the scope of the process demonstrated that the effectiveness of ligand $\mathbf{L 9}$ is fairly general across a range alkenylazaarenes and arylboronic acids. Further experimental and theoretical ${ }^{14}$ investigations of anilidecontaining chiral dienes in asymmetric catalysis are planned, and will be reported in due course.

This work was supported by the EPSRC, Pfizer, and the University of Edinburgh. The EPSRC is gratefully acknowledged for the award of a Leadership Fellowship to H.W.L. We thank Dr. Gary S. Nichol and Stewart Franklin at the University of Edinburgh for X-ray crystallography and technical assistance, respectively. We thank the EPSRC National Mass Spectrometry Facility for providing high-resolution mass spectra.

\section{Notes and references}

1 (a) L. Rupnicki, A. Saxena and H. W. Lam, J. Am. Chem. Soc., 2009, 131, 10386-10387. (b) G. Pattison, G. Piraux and H. W. Lam, J. Am. Chem. Soc., 2010, 132, 14373-14375. (c) A. Saxena, B. Choi and H. W. Lam, J. Am. Chem. Soc., 2012, 134, 8428-8431. (d) C. Fallan and H. W. Lam, Chem. Eur. J., 2012, 18, 11214-11218. (e) D. Best, S. Kujawa and H. W. Lam, J. Am. Chem. Soc., 2012, 134, 18193-18196. (f) A. J. Simpson and H. W. Lam, Org. Lett., 2013, 15, 2586-2589.

2 D. Best and H. W. Lam, J. Org. Chem., 2014, 79, ASAP, DOI: $10.1021 /$ jo402414k

3 For Ni-catalyzed additions of organometallics to 4-alkenylpyridines with low enantioselectivities ( $\leq 15 \%$ ee), see: I. N. Houpis, J. Lee, I. Dorziotis, A. Molina, B. Reamer, R. P. Volante and P. J. Reider, Tetrahedron, 1998, 54, 1185-1195.

4 For catalytic asymmetric Michael additions of nitroalkanes and anthrone to 4-nitro-5-styrylisxoxazoles, see: (a) A. Baschieri, L. Bernardi, A. Ricci, S. Suresh and M. F. A. Adamo, Angew. Chem., Int. Ed., 2009, 48, 9342-9345. (b) H.-W. Sun, Y.-H. Liao, Z.-J. Wu, H.-Y. Wang, X.-M. Zhang and W.-C. Yuan, Tetrahedron, 2011, 67, 3991-3996. 
5 A seminal reference: M. Sakai, H. Hayashi and N. Miyaura, Organometallics, 1997, 16, 4229-4231.

6 The first enantioselective example: Y. Takaya, M. Ogasawara, T. Hayashi, M. Sakai and N. Miyaura, J. Am. Chem. Soc., 1998, 120, 5579-5580.

7 For reviews, see: (a) T. Hayashi and K. Yamasaki, Chem. Rev., 2003, 103, 2829-2844. (b) Yoshida, K.; Hayashi, T. In Modern Rhodium-Catalyzed Organic Reactions; Evans, P. A., Ed.; WileyVCH: Weinheim, 2005; Chapter 3, p 55-77. (c) H. J. Edwards, J. D. Hargrave, S. D. Penrose and C. G. Frost, Chem. Soc. Rev., 2010, 39, 2093-2105. (d) P. Tian, H.-Q. Dong and G.-Q. Lin, ACS Catalysis, 2011, 2, 95-119.

8 For a review of Rh-catalyzed carbon-carbon bond-forming reactions of organometallic compounds, see: K. Fagnou and M. Lautens, Chem. Rev., 2003, 103, 169-196.

9 For seminal references describing chiral dienes in asymmetric catalysis, see: (a) T. Hayashi, K. Ueyama, N. Tokunaga and K. Yoshida, J. Am. Chem. Soc., 2003, 125, 11508-11509. (b) C. Fischer, C. Defieber, T. Suzuki and E. M. Carreira, J. Am. Chem. Soc., 2004, 126, 1628-1629.

10 For reviews of chiral diene ligands, see: (a) R. Shintani and T. Hayashi, Aldrichimica Acta, 2009, 42, 31-38. (b) J. B. Johnson and T. Rovis, Angew. Chem., Int. Ed., 2008, 47, 840-871. (c) C. Defieber, H. Grutzmacher and E. M. Carreira, Angew. Chem., Int. Ed., 2008, 47, 4482-4502.

11 For selected, recent examples of chiral dienes in catalytic asymmetric 1,4- and 1,6-addition reactions, see: (a) C. Shao, H.-J. Yu, N.-Y. Wu, P. Tian, R. Wang, C.-G. Feng and G.-Q. Lin, Org. Lett., 2011, 13, 788-791. (b) K. Sasaki and T. Hayashi, Tetrahedron: Asymmetry, 2012, 23, 373-380. (c) T. Nishimura, A. Noishiki and T. Hayashi, Chem. Commun., 2012, 48, 973-975. (d) Y.-C. Chung, D. Janmanchi and H.-L. Wu, Org. Lett., 2012, 14, 2766-2769. (e) K. Sasaki, T. Nishimura, R. Shintani, E. A. B. Kantchev and T. Hayashi, Chem. Sci., 2012, 3, 1278-1283. (f) T. Nishimura, Y. Takiguchi and T. Hayashi, J. Am. Chem. Soc., 2012, 134, 90869089. (g) Z.-T. He, Y.-B. Wei, H.-J. Yu, C.-Y. Sun, C.-G. Feng, P. Tian and G.-Q. Lin, Tetrahedron, 2012, 68, 9186-9191. (h) H.-J. Yu, C. Shao, Z. Cui, C.-G. Feng and G.-Q. Lin, Chem. Eur. J., 2012, 18, 13274-13278. (i) J. Keilitz, S. G. Newman and M. Lautens, Org. Lett., 2013, 15, 1148-1151. (j) M. M. Hansmann, A. S. K. Hashmi and M. Lautens, Org. Lett., 2013, 15, 3226-3229. (k) A. A. Friedman, J. Panteleev, J. Tsoung, V. Huynh and M. Lautens, Angew. Chem., Int. Ed., 2013, 52, 9755-9758.

12 For Rh-catalyzed additions of arylboronic acids to vinylazaarenes resulting in achiral products, see: (a) M. Lautens, A. Roy, K. Fukuoka, K. Fagnou and B. Martín-Matute, J. Am. Chem. Soc., 2001, 123, 5358-5359. (b) R. Amengual, V. Michelet and J.-P. Genêt, Tetrahedron Lett., 2002, 43, 5905-5908.

13 For application of a simpler amide-containing chiral diene $\mathbf{L 5}$ in enantioselective rhodium-catalyzed arylations of electron-deficient alkenylarenes, including a 5-nitro-2-alkenylpyridine, see: A. Saxena and H. W. Lam, Chem. Sci., 2011, 2, 2326-2331.

14 For computational studies of chiral diene ligands, see ref. 11e and: (a) E. A. B. Kantchev, Chem. Commun., 2011, 10969-10971. (b) S.
Gosiewska, J. A. Raskatov, R. Shintani, T. Hayashi and J. M. Brown, Chem. Eur. J., 2012, 18, 80-84. (c) Y. Luo, N. G. Berry and A. J. Carnell, Chem. Commun., 2012, 48, 3279-3281. (d) E. A. B. Kantchev, Chem. Sci., 2013, 4, 1864-1875. 